\title{
Simulation of trends in the use of e-payment using agent-based models
}

\author{
Elanjati Worldailmia ${ }^{*}$, Ismiantib \\ a Industrial Engineering, Universitas Islam Indonesia, Kaliurang Road Km.14.5, Sleman \\ ${ }^{\mathrm{b}}$ Industrial Engineering, Universitas Pembangunan Nasional Veteran Yogyakarta, SWK Street 104, Sleman
}

*Corresponding Authors: elanjati.worldailmi@uii.ac.id

\section{ARTICLE INFO ABSTRACT}

\section{Keywords}

Agent-Based

Modelling and

Simulation (ABMS);

E-payment;

Cashless.
Bank Indonesia $(\mathrm{BI})$ as the central bank in Indonesia has launched a movement to use non-cash instruments in conducting transactions on economic activities to reduce the money supply, reduce crime rates, and reduce $\mathrm{BI}$ operational costs. The country's economic policy factors, the availability of various non-cash payments, and online sales and purchases can encourage the tendency to use non-cash transactions (e-payment). One way to find out these trends is to use a model. Models can help understand and explain real phenomena more easily and efficiently than directly observing. One model that can be used is Agent-Based Modeling and Simulation (ABMS). By using ABMS, the development of models with complex behaviors, dependencies, and interactions can be developed more easily. ABMS is able to describe processes, phenomena, and situations. In this study, the factors that influence the trends to use epayment are obtained from various references. These factors include perceived security, performance expectancy, effort expectancy, culture, satisfaction, social influence, age, income, ownership of e-payment accounts, and education level. In simulations using ABMS, detailed descriptions explained based on ODD Protocol elements can be more easily understood and complete. ODD systematically evaluates a model. From the simulation results, the number of e-payment users follows the Scurve pattern. The pattern is rising and falling steadily, then sharply rising, and then rising and falling stably again. From the sensitivity analysis, perceived security, performance expectancy, and effort expectancy have an important role in this trend.

\section{Introduction}

Bank Indonesia (BI) as the central bank in Indonesia has launched the National Non-Cash Movement (GNTN), which is the movement of using non-cash instruments (Less Cash Society/LCS) specifically in conducting transactions in accordance with economic activities (Fahmi, 2016). This is done to reduce the amount of money spent, reduce crime, and reduce the operational costs of Bl to buy, save, calculate, and destroy money every year. According to the Director of Payment Policy and Supervision System (DKSP) BI, non-cash transactions can be done with cash. This move to non-cash can also reduce the level of money in Indonesia because high circulation will increase the Indonesian economy. The majority of Indonesian people are ready to trade without cash (cashless society). This involves research conducted by Visa titled Consumer Payment Attitudes 2018. This study shows the number of digital literate customers is growing in Southeast Asia and calculates that Indonesians are increasing the benefits of noncash payments and are interested in a tax-free future. Several red plate banks and private banks have also issued non-cash payment instruments such as net banking, mobile banking, and virtual 
payments (electronic payments). In addition, non-cash payment applications such as Go-Pay, OVO, Funds, etc. are becoming increasingly numerous and usable. In addition to various types of payments, online sales are increasing.

The country's economic policy factors, the availability of various non-cash payments and online sales and purchases encourage the tendency to use non-cash transactions (e-payments) that can be examined. One way to find out these options is to use models. Models can help answer and explain real phenomena more easily and efficiently for direct observation (Wilensky and Rand, 2015). The model also explains the basis on which the phenomena are based. One model that can be used is Agent-Based Simulation and Modeling (ABMS). ABMS began as a computational social science representing social reality, which was agented as an agent and the environment (Gilbert, 2007). By using ABMS, the development of models with behaviors, dependencies, and interactions that are easily developed more easily (Borshchev and Filippov, 2004). ABMS is a computational model that makes it possible to describe the behavior of agents and their interactions, so they are able to imagine processes, phenomena, and movements. ABMS is new which makes its agents stand-alone with autonomy and mutual assistance (Macal and North, 2008).

\section{Literature Review}

ABMS was originally a computational social science that represented social reality, in which there were an agent and environment (Gilbert, 2007). By using ABMS, the development of models with complex behaviors, dependencies, and interactions can be developed more easily (Borschchev and Filippov, 2004). ABMS is a computational model that allows describing the behavior of agents and their interactions so that they are able to describe processes, phenomena, and situations. ABMS is a new approach that makes agents autonomous and interact with each other (Macal and North, 2008).

One method for solving problems is to use simulations (Fajri, 2018). Through simulation, factors that affect the system and changes in the system can be seen. There are various ways to do the simulation. One simulation method that can be used is agent-based modeling, namely Agent-Based Modeling and Simulation (ABMS). ABMS is one of the modeling methods that can simulate interactions between agents (individuals) in a system. As a result, the system model and individual effects in the system can be easily seen. Models can help understand and explain real phenomena more easily and efficiently than directly observing (Wilensky and Rand, 2015). The model also explains the basic mechanisms that are based on existing phenomena.

Each individual has different characteristics and behaviors from one another. If the agents interact, unpredictable behavior can occur (emergence behavior). The ability of agents to determine behavior is called self-organization.

There are some differences between ABMS and another modeling. First, Agent-Based Modeling can describe heterogeneous populations or consider agents that have different properties. Meanwhile, in most other models, the population is considered homogeneous. Second, Agent-Based Modeling does not require knowledge of the phenomenon as a whole, but only knowledge of individual behavior. Furthermore, Agent-Based Modeling is closer to the real system because it models the behavior of each different individual. Agent-Based Modeling is modeled in more detail using the "bottom-up" method so that it can see the individual level and the aggregate level at the same time.

There are various software that can be used for ABMS, including NetLogo, Repast, Starlogo, $\mathrm{C}, \mathrm{C}_{++}$, Java or Pascal. From some of the software, software that is often used is NetLogo. 
NetLogo uses a relatively easy programming language, is able to change views that are easy to understand, and can be operated on all operating system platforms (Mac, Window, Linux, etc.). NetLogo is software that can be used to model a system and can give orders to its agents so that they can describe the nature of different agents and form complex systems.

There are four types of agents in NetLogo, namely turtle, patches, link, and observer. Turtle is an agent that moves in the environment and can interact with patches or other agents. Patch, a place for moving agents that can form the environment. Link is a link between two turtles in the environment. The observer is an external agent that can manipulate all agents in the environment.

From previous studies, factors that influence the use of e-payment can be influenced by usefulness, easy to use, satisfaction, compulsion, network externality, and norms (Dehbini et al., 2015). In other studies in Indonesia, factors that influence the use of e-payment include culture, perceived security, performance expectancy, effort expectancy, and social influence (Junadi and Sferianto, 2015). These factors are explained in Table 1.

Factors influencing the use of e-payment from previous studies (Dehbini et al., 2015; Junadi and Sferianto, 2015) were then selected by experts and obtained factors used in this study, namely satisfaction, culture, social influence, norm, network externality, perceived security, performance expectancy, and effort expectancy. Social influence, norms, and network externality in this model are considered to be the same parameters represented by social influence.

The use of e-payment is inseparable from individual factors such as age, education, employment, income (Nisa et al., 2013; Sihotang, 2016). Age and education also enter into the cultural factor (Junadi and Sferianto, 2015). In addition to these individual factors, a person's preference for e-payment is also driven by the ownership of an e-payment account, the benefits of e-payment, the attractiveness of e-payment, and the loss of e-payment (Yudhistira P, 2014). From these factors, the chosen factors in describing someone's threshold in using e-payment include age, income, e-payment account ownership, and education.

\section{Table 1. The Factors of Using E-Payment}

DEHBINI ET AL. (2015)

Satisfaction: satisfaction using epayment

- $\quad$ Compulsion: must use e-payment (such as school regulations for school payments or office regulations for salary payments)

- $\quad$ Easy to use: ease of use

- Usefulness: usability

- Norms: norms / views / habits in using epayment

- Network externality: the influence of people around who use or not use epayment

Perceived security, performance expectancy and effort expectancy are assumed to be integrated as an average factor. Cultural factors are represented at the education level (at least undergraduate or not). Satisfaction can be seen from the level of e-payment user satisfaction. Social influence is a result of the level of satisfaction of e-payment users. If satisfied, influence others to use e-payment. If not satisfied, influence others not to use. The age is divided into the

\section{JUNADI \& SFERIANTO (2015)}

Culture: internet access, experience, and education level in using e-payment

- Perceived security: technical protection, security, and government and bank policies in using e-payment

- Performance expectancy: productivity and speed in using e-payment

- Effort Expectancy: ease and flexibility in using e-payment

- Social influence: the influence of people around who use or not use e-payment 
productive age for using e-payment and the non-productive age. Income is divided into an income of at least Rp 2.5 million or below. Income considerations are the average minimum wage income in Indonesia.

\section{Research Methodology}

In simulations using ABMS, detailed descriptions are explained based on the overview design concept, and details protocol elements (Grimm et al., 2010). The main purpose of ODD is to make a model more easily understood and complete. ODD systematically evaluates a model. The advantage is that ODD can improve the accuracy of model formulas and make the theoretical basis more visible. ODD documents large and complex models. The ODD Protocol explains the purpose, entities, state variables, and scales, process overview and scheduling, design concepts (basic principles, emergencies, adaptations, objectives, learning, prediction, sensing, interaction, stochasticity, collectives, and observation), initialization, input data, and submodels. In this study, the factors that influence the tendency to use e-payment are obtained from various references. From these factors, then created a scenario as a sub-purpose of this model.

From the references, there are several factors that influence the use of e-payment. Agents built on this model include people (users and non-users), shops, and e-payment providers (in this case, we refer to as "APPE"). In this case, APPE is represented by the bank. The simulation flow is shown in Figure 1.

Someone can make transactions using e-payment if the age, income, account, and education factors are met through the total score. The score for age, in this case, is referred to as "scores". Scores for earnings for this case are referred to as "scores". When there are buyers who use epayment in a store, the buyer can feel satisfied or unsatisfied in using e-payment. This satisfaction is influenced by the factors of the tendency to use e-payment as well as how the service from the store. The level of service from the store to the buyer, in this case, is referred to as "services". The store service value is influenced by the services of the e-payment provider agency (APPE). The level of service APPE, in this case, we refer to as "serviceappe".

If the buyer feels satisfied, then when meeting with others will have a positive influence and invite others to join using e-payment. In this case, we refer to as "yes influence". Conversely, if the buyer feels dissatisfied, then when meeting with others will have a negative influence and invite others not to use e-payment. In this case, we refer to as "no influence". 


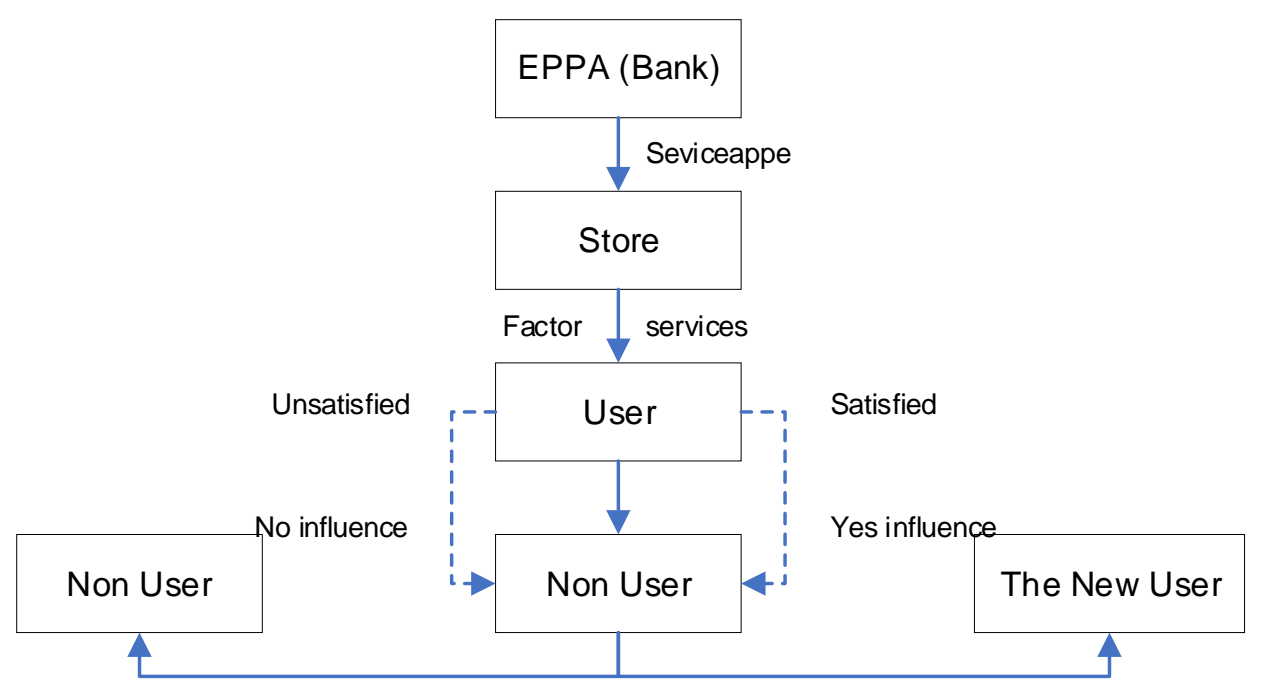

Figure 1. The Simulation Flow

There are several assumptions used in this study. Assumptions used include: one tick is assumed as a unit of time; the store can have e-payment services of 0 to 10 merchants (banks/institutions providing e-payment) randomly; each person makes a purchase in one unit of time, each person who has ever transacted, when meeting with other people can influence others to use or not use e-payment; buyer satisfaction is influenced by store service and average factors; store service is influenced by the services of e-payment providers, which in this case represented by the services of the bank; if the store service value is low, then the bank can provide extra services to the store so that the shop also improves service to buyers which can ultimately increase buyer satisfaction. When people who have ever transacted with e-payments are satisfied, they will provide assistance to others to use, or what we call "yes influence". Conversely, if the person is not satisfied, then he will influence others not to use, or we call it "no influence". ABMS simulation in this study uses NetLogo.

\section{Results and Discussion}

\subsection{ODD Protocol}

The ODD protocol describes various elements for a detailed description of an agent-based model. In this study, the ODD Protocol elements used are overview, design concept, and details. Overview elements include purpose; entities, state variables and scale; and process overview and schedule. Design concepts include basic principles, emergences, adaptation, objectives, learning, prediction, sensing, interaction, stochasticity, collectives, and observation. Details include initialization, input data, and submodels. This research has no elements of adaptation, learning, prediction, sensing, collectives, and input.

\section{a. Purpose}

The main purpose of this model is to model the tendency of using e-payment which is influenced by various factors, such as perceived security, performance expectancy, effort expectancy, culture, satisfaction, social influence, age, income, account ownership, and 
education obtained from Dehbini et al. (2015), Junadi and Sferianto (2015), Nisa et al (2013), Sitohang (2016), and Yudhistira P (2014).

With several scenarios, the sub-purpose of this model is to determine the effect of average factors (perceived security, performance expectancy, effort expectancy) on the number of epayment users (1), know the effect of bank services on store services and the number of epayment users (2).

b. Entities, State Variable, dan Scales

Entities, state variables, and scales explain the types of agents, attributes, behavior, and environment used in modeling. The types of agents, attributes, and behavior are shown in Table 2. In this model, there is no environment.

Table 2. Types of Agents, Attributes, and Behaviors

\begin{tabular}{|c|c|c|}
\hline $\begin{array}{c}\text { TYPES OF } \\
\text { AGENTS }\end{array}$ & ATTRIBUTES & BEHAVIORS \\
\hline $\begin{array}{l}\text { People / } \\
\text { Population } \\
\text { (Users and } \\
\text { Non-Users) } \\
\text { (mobile agent) }\end{array}$ & 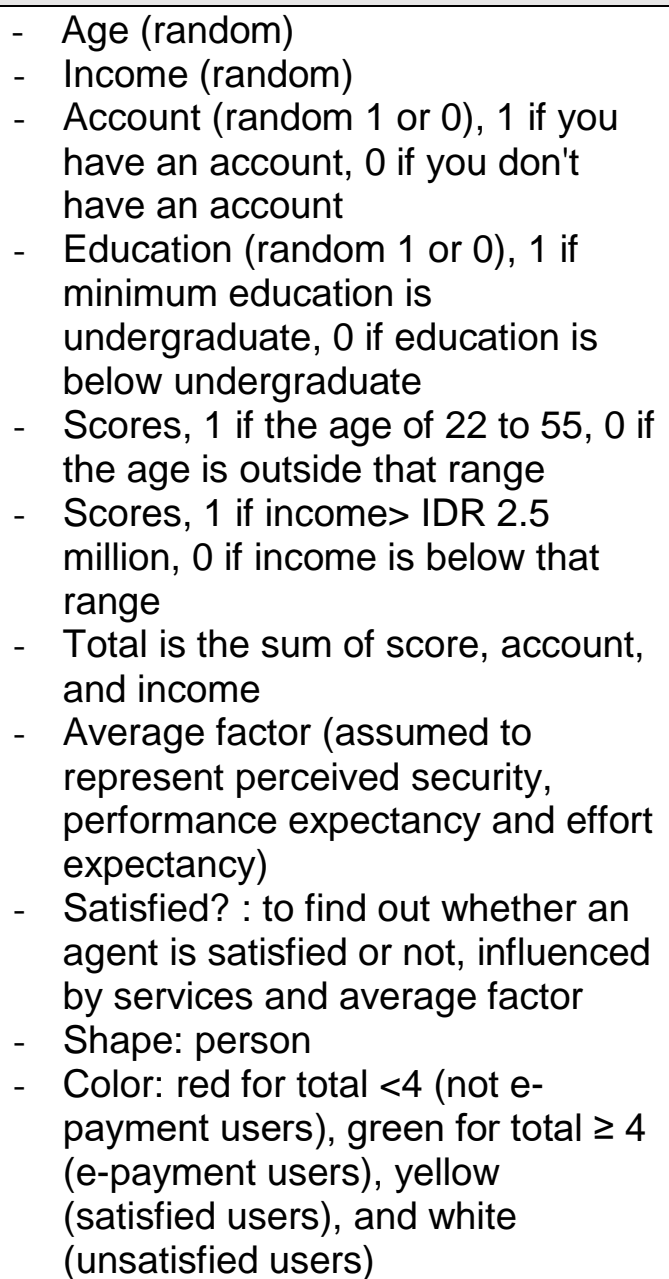 & $\begin{array}{l}\text { - Move: people will move to the } \\
\text { store to buy every } 1 \text { tick } \\
\text { - Transactions: People will trade } \\
\text { using e-payments with stores if } \\
\text { the age, income, account, and } \\
\text { education factors meet. } \\
\text { Transaction people will feel } \\
\text { satisfied if the store provides } \\
\text { good service (services) and the } \\
\text { average factor value is met. } \\
\text { - Yes influence: People will give } \\
\text { the effect of adding a total value } \\
\text { to others if satisfied (the value of } \\
\text { adding } 5 \% \text { ). } \\
\text { - No influence: People will give the } \\
\text { effect of reducing the total value } \\
\text { to others if they are not satisfied } \\
\text { (5\% reduction value). }\end{array}$ \\
\hline
\end{tabular}




\begin{tabular}{|c|c|c|}
\hline $\begin{array}{c}\text { TYPES OF } \\
\text { AGENTS }\end{array}$ & ATTRIBUTES & BEHAVIORS \\
\hline $\begin{array}{l}\text { Store } \\
\text { (stationery } \\
\text { agent) }\end{array}$ & $\begin{array}{l}\text { - Number of APPE (E-Payment } \\
\text { Provider Agencies), where each } \\
\text { APPE has a service value } \\
\text { (serviceappe) } \\
\text { - Services obtained from the average } \\
\text { APPE service value owned } \\
\text { - Shape: house } \\
\text { - Color: blue for stores that do not } \\
\text { provide e-payment (services }=0 \text { ) } \\
\text { and blue-yellow for stores that } \\
\text { provide e-payment (services }>0 \text { ) }\end{array}$ & $\begin{array}{l}\text { - Transactions: stores will make e- } \\
\text { payment transactions with people } \\
\text { (buyers) if the buyers who come } \\
\text { to the store are e-payment users. } \\
\text { - Improvements: Stores will make } \\
\text { improvements by adding the } \\
\text { value of the store service } \\
\text { (services) if the services }<40 \text { and } \\
\text { the average factor }<40 \text {. }\end{array}$ \\
\hline $\begin{array}{l}\text { Bank (mobile } \\
\text { agent) }\end{array}$ & $\begin{array}{l}\text { - Shape: a business person } \\
\text { - Color: white }\end{array}$ & $\begin{array}{l}\text { - Move: The bank will move to } \\
\text { stores that have services }<40 \text {. } \\
\text { - Service: The bank will add the } \\
\text { average factor value to the shops } \\
\text { visited so that the store can } \\
\text { improve services which can } \\
\text { ultimately provide satisfaction to } \\
\text { the buyer. }\end{array}$ \\
\hline
\end{tabular}

\section{Process Overview dan Scheduling}

This model was built to see someone's trend to use e-payment. The average factor is a percentage value that influences the satisfaction of buyers/people in using e-payment. The satisfaction of buyers/people in using e-payment is influenced by service from the store and the average factor. Service from a store is influenced by serviceappe (average APPE service owned by a store). If the store provides bad service $(<40)$, the bank represented by the agent/marketing bank will come to the shop to provide extra service so that the store can improve its services. In this case, the bank will increase the average factor value. Satisfied buyer/person will influence others to use e-payment (yes influence). Conversely, buyers/people who are dissatisfied will influence others not to use e-payment (no influence). In initialization, the observer can determine the number of populations, number of stores, number of banks, and average factor. The population is limited to 300 people, the number of stores is limited to 100, and the number of banks (marketing/bank people) is limited to 50 people.

The mechanism of this model is:

- Perceived security, performance expectancy and effort expectancy are sliders with certain values that affect buyer satisfaction in addition to service from the store. These three factors are described in the slider average factor.

- The sum of individual factors, namely age, income, e-payment account ownership, and education level shows the percentage of propensity/probability of using e-payment. Age and income are built with random values which are then categorized into 2 values, namely 1 and 0 so that when a sum is made on these factors a value of 4 is obtained. 
- If the sum of individual factors reaches 4, then that person will use e-payment. If it is less than this value, then people will not use e-payment.

- Stores will serve buyers with certain service values that can have an effect on customer satisfaction, besides the average factor.

- If the buyer feels satisfied, then the buyer will invite others to make purchases through epayment (network externality factor). However, if the buyer feels dissatisfied, then the buyer will invite others not to make purchases through e-payment / cash payment (network externality factor).

- Stores can have as many as 0 to 10 merchant random e-payment media. If the store has 0 merchants, it means that payments can only be made in cash.

- The store service value depends on the service value of the E-Payment Provider Agency (APPE). If the average value of APPE services owned by a store is more than 40 , the store will provide good service to the buyer, with the value of service to the buyer equal to the average value of APPE services to the store.

\section{d. Basic Principle}

Based on the theory, factors that influence the use of e-payment that have been selected for use in this study include perceived security, performance expectancy, effort expectancy, culture, satisfaction, social influence, age, income, e-payment account ownership, and education. From these factors, perceived security, performance expectancy, and effort expectancy are the parameters displayed by the slider. These three things are incorporated into the slider average factor. Age, income, e-payment account ownership, and education are random values that determine a person's trends to use e-payment. Satisfaction and social influence (that represent norms and network externalities) are defined as emergent conditions (satisfied or unsatisfied, yes influence and np influence).

In this study, age and income are categorized into two categories built from random values. Ownership of e-payment and education accounts is assumed to be a yes-no question, in which the categorization of e-payment account ownership is divided into two, namely having an account or not having an account, and categorizing for education is divided into two, at least undergraduate or not undergraduate.

\section{e. Emergences}

Emergence in this model is the number of e-payment users affected by The influence of other people's invitations to use or not use e-payments (yes influence and no influence), how the store service (services), and how other factors influence (average factor is representing perceived security, performance expectancy and effort expectancy factors

\section{f. Objectives}

Objectives in this model include people (getting satisfaction using e-payment), shops (getting as many buyers as possible, including through e-payment and getting good service from banks (those who provide help to provide e-payment), banks (have as many customers (e-payment provider stores) as possible, collect as much funds (via e-payment) as possible, provide good service to customers/e-payment provider stores). 


\section{g. Interaction}

Interactions on this model include people with people (e-payment users not e-payment users), people with stores, shops with APPE, shops with banks.

\section{h. Stochasticity}

Stochasticity in this model is a random value that is built for age, income, number of accounts, level of education, number of APPE, APPE service, and movement of people.

\section{i. Observation}

In this model, the number of users, number of non-users, number of satisfied users, number of e-payment provider shops and number of non-e-payment shops are observed.

j. Initialization

Initialization in this model includes the average factor value, number of banks, number of shops, population/people.

k. Submodel

Submodel in this model is to know the effect of average factors (perceived security, performance expectancy, effort expectancy) on the number of e-payment users and to know the effect of bank services on store services and the number of e-payment users.

\subsection{Analysis}

Sensitivity analysis is done by repetition 3 times and time limit 200 . With the initialization of the population of 200 people and the number of shops as many as 50 stores. With the following 4 scenarios:

a. Average factor 70 (many) with a bank number of 0 (no bank)

b. Average factor 10 (few) with a bank number of 0 (no bank)

c. Average factor 70 (many) with a bank number of 10 (with a bank)

d. Average factor 10 (few) with a bank number of 10 (with a bank)

Before conducting a comparison test of various scenarios, before each scenario was tested to see whether the repetition generated from the model is consistent. The following are the results of each test.

a. Comparison of repetitions with the same parameters.

The results of testing on each parameter are the same which are no significant differences. In this report, the results of repetition testing on the same parameter are only displayed for 2 parameters only.

- Average-factor parameter 70, number of banks 0

From the results of the t-test for equality of means, the significance value is 0.371 .

- Average-factor parameter 70, number of banks 10

From the results of the t-test for equality of means, the significance value is 0.931 .

b. Comparison of the number of people who use and not use e-payment with a factor of 70 and a factor of 10 with a bank 0 . The results of testing on these 2 parameters found a 
significant difference. From the results of the t-test for equality of means, the significance value is 0.00 .

c. Comparison of the number of e-payment users with the same factors of 70 but the number of banks is different. In testing with the same factors but the number of different banks found insignificant differences. From the results of the t-test for equality of means, the significance value is 0.215 .

d. Comparison of the number of e-payment users with a factor of 10 but the number of banks is different. In testing with the same factor but the number of different banks obtained significantly different results. From the results of the t-test for equality of means, the significance value is 0.00 .

e. Comparison of the number of e-payment users with a factor of 70 and 10 and the number of banks together 10. In testing with the same factor but the number of different banks obtained significantly different results. From the results of the t-test for equality of means, the significance value is 0.035 .

Comparison aims to find out how the influence of the number of banks and the influence of the average factor. From the four scenarios, statistical tests are performed to see the comparison of experimental results. Testing is done by an independent t-test with SPSS 16.0 software. The following table 3 explains the results of statistical tests for the 4 scenarios.

Table 3. Statistical Testing Results

\begin{tabular}{|c|c|c|c|c|}
\hline \multicolumn{2}{|c|}{ PARAMETER 1} & \multicolumn{2}{|c|}{ PARAMETER 2} & \multirow[b]{2}{*}{$\begin{array}{c}\text { STATISTICAL TESTING } \\
\text { RESULTS }\end{array}$} \\
\hline $\begin{array}{c}\text { BANK } \\
\text { AMOUNT }\end{array}$ & $\begin{array}{l}\text { AVERAGE } \\
\text { FACTOR }\end{array}$ & $\begin{array}{c}\text { BANK } \\
\text { AMOUNT }\end{array}$ & $\begin{array}{l}\text { AVERAGE } \\
\text { FACTOR }\end{array}$ & \\
\hline 0 & 70 & 0 & 10 & Significant differences \\
\hline 0 & 70 & 10 & 70 & $\begin{array}{c}\text { The difference is not } \\
\text { significant }\end{array}$ \\
\hline 0 & 10 & 10 & 10 & Significant differences \\
\hline 10 & 70 & 10 & 10 & Significant differences \\
\hline
\end{tabular}

If the average factor value is high, whatever the number of banks supporting the e-payment does not affect the tendency to use e-payment. Conversely, if the average factor value is low, differences in the number of banks affect how the tendency to use e-payment. The average factor greatly influences the tendency to use e-payment. So, from the results of this case simulation, perceived security, performance expectancy, and effort expectancy influence the tendency to use e-payment. This is in line with the research of Junadi and Sferianto (2015). From the simulations that have been carried out on the propensity to use e-payment models, the results are quite interesting. The number of e-payment users will continue to increase following the s-curve pattern if users are satisfied and the surrounding factors support. 


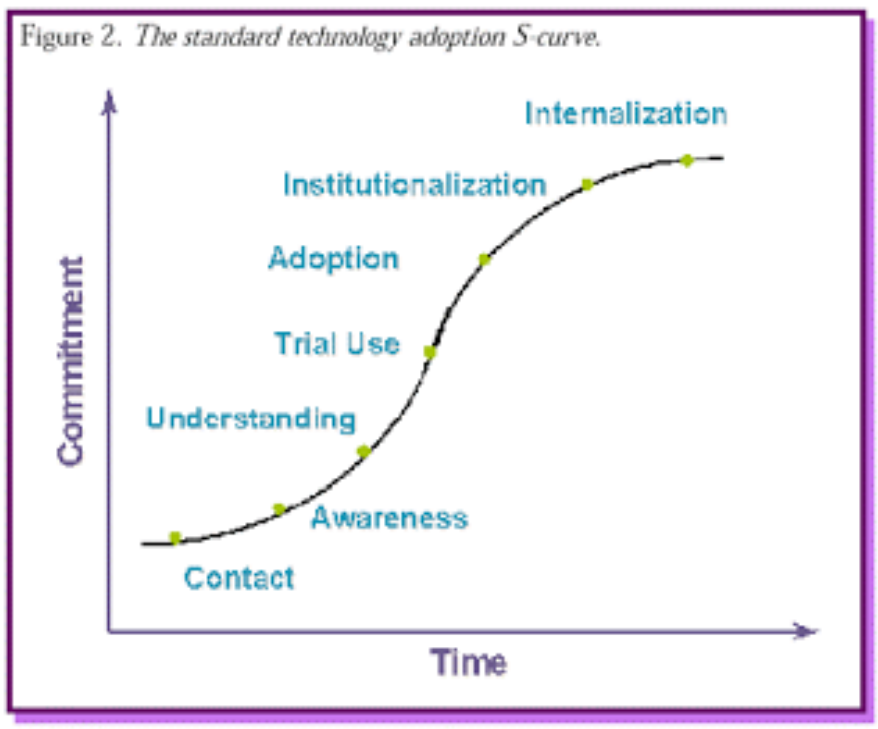

Figure 2. S-shaped technology adoption graphics standard chart

From the simulations that have been carried out on the e-payment tendency model, the results are quite interesting. The number of e-payment users will continue to increase following the s-curve pattern if users are satisfied and the surrounding factors support. Figure 3 below is one graph of emergent numbers of e-payment users in one simulation.

From the simulation results, it can be seen that the number of e-payment users at the beginning is quite stable up and down then after a while it will increase quite rapidly (a sharp increase) but after that, the ups and downs will return stable. This turned out to follow the s-curve where this s-curve illustrates the adoption of many new technologies. Rogers (1983) states, "Tarde's S-shaped diffusion curve is of importance because" most innovations have an S-shaped rate of adoption ". Figure 2 below is an S-shaped graph. The theory about S-shaped is a tool to validate and verify the results of simulation models related to the use of e-payment.

\section{Conclusion}

Transactions with non-payment (e-payment) have various benefits for the community such as reducing the money supply, reducing crime rates, and reducing operational costs. E-payment usage factors include perceived security, performance expectancy, effort expectancy, culture, satisfaction, social influence, age, income, e-payment account ownership, and education level. In the simulation, perceived security, performance expectancy, and effort expectancy are depicted from the average factor value. While age, income, e-payment account ownership, and education are the initial factors before the implementation of transactions using e-payment. E-payment satisfaction is influenced by average factors (perceived security, performance expectancy, and effort expectancy) and service satisfaction from e-payment provider stores. How the store service is affected by the services of e-payment providers described as banks. If the buyer is satisfied or not satisfied, he will influence others to use or not use it. 
From the simulation results, the number of e-payment users steadily rises and falls, then rises sharply, and then rises and falls steady again. The pattern follows the S-curve pattern if the user is satisfied and the surrounding factors support. S-curve describes the adoption of many new technologies. When viewed from a sensitivity analysis, in conditions with a high average factor value, whatever the number of e-payment providers does not affect the tendency to use epayment. That is, perceived security, performance expectancy, and effort expectancy have an important role in this tendency. The research conducted has limitations such as real data (in the field) and richer factors from various references. In addition, for future research, it can be varied with various e-payment media.

\section{References}

Borshchev, A. \& Filippov, A. (2004). From System Dynamics and Discrete Event to Practical Agent-Based Modeling: Reasons, Techniques, Tools. Proceedings of the 22nd International Conference of the System Dynamics Society, Oxford, England.

Dehbini, N., Birjandi, M., \& Birjandi, H. (2015). Factors Influencing the Adoption of Electronic Payment Cards in Urban Micro-Payments. Research Journal of Finance and Accounting,16(1), 2015.

Fahmi, S.C. (2016). Analysis of Factors Affecting Community Preferences Using Cash Transactions (Case Study of 5 College Students in Yogyakarta). Scientific Journal of Economic Study Program FEB UMY.

Fajri, M. (2018). Simulation with Agent-Based Modelling, http://psti.ft.ugm.ac.id/2018/10/09/simulation-with-agent-based-modelling/. Accessed 16 Oktober 2019.

Gilbert, N. (2007). Agent-Based Models. University of Surrey: The Centre for Research in Social Simulation, epubs.surrey.ac.uk/cress/13.

Grimm, V., Berger, U., DeAngelis, D.L., Polhill, J.G., Giske, J., \& Railsback, S.F. (2010). The ODD Protocol, A Review and First Update. Ecological Modelling 221 (2010) 2760-2768.

Junadi \& Sfenrianto. (2015). A Model of Factors Influencing Consumer's Intention to Use EPayment System in Indonesia. Procedia Computer Science 59 (2015) 214-220.

Macal, C.M. \& North, M.J. (2008). Agent-Based Modeling and Simulation: ABMS Example. Proceedings of the 2008 Winter Simulation Conference.

Nisa, D.D. Ariyani, T.S., \& Oktaviani, K. (2013). Analysis of Factors Affecting Customers Using Mandiri Internet Banking Services. Journal of Management Vol 13 No 1 November 2013. 
Rogers, E. (1995). Diffusions of Innovations,

http://web.stanford.edu/class/symbsys205/Diffusion\%20of\%20Innovations.htm. Accessed 30 Mei 2017.

Sitohang, E.T. (2016). Determinants That Influence Use of Internet Banking Services. Mediterranean Journal of Social Sciences, 3(5), 33-41.

Wilensky, U. \& Rand, W. (2015). An Introduction to Agent-Based Modeling. Cambridge, Massachusetts: The MIT Press.

Yudhistira P., A. (2014). Analysis of Factors Influencing Preference and Accessibility to the Use of Electronic Payment Cards. Scientific Journal of the Department of Economics Faculty of Economics and Business, Universitas Brawijaya Malang. 
This page is intentionally left blank. 